\title{
Oncology Referral Concerning Paediatric Neurosurgery? Analysis of the Situation between 2008-2013 in the North of Portugal
}

\author{
Referenciação Oncológica em Neurocirurgia Pediátrica? \\ Análise da Situação no Norte de Portugal entre 2008-2013
}

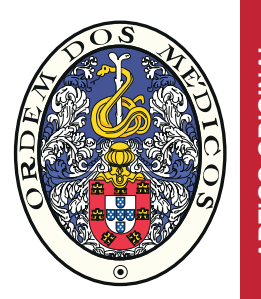

Ana BATISTA ${ }^{1} 1$, Luís NOGUEIRA-SILVA ${ }^{2,3}$, Rui VAZ ${ }^{4,5}$, Joana OLIVEIRA ${ }^{4,5}$

Acta Med Port 2016 Jan;29(1):15-23

\section{ABSTRACT}

Introduction: Primary central nervous system tumours represent the second most frequent neoplasm and are the leading cause of death from solid tumours in children. Our study aimed to provide the most up-to-date epidemiological analysis of primary central nervous system tumours in children living in the north of Portugal and to explore a possible effect of the centralisation of care on outcomes.

Material and Methods: This population-based study included all newly diagnosed and histologically confirmed primary central nervous system tumours in people below 18 years old, living in the north of Portugal, from January 2008 to December 2013. Data were collected through access to clinical files. We described children and tumour characteristics, and analysed patient: paediatric neurosurgeon and histological tumour type: paediatric neurosurgeon ratios.

Results: A total of 147 cases was recorded. Mean age at diagnosis of primary central nervous system tumours was $8.0 \pm 5.2$ years. Astrocytomas were the most common histological type (34\%). We found that World Health Organization Tumour Grade was the only variable of statistically significant influence in mortality $(p=0.001) .1$-, 3- and 5-year survivals related to $2008-2013$ period were statistically higher than 2005 - 2007. Astrocytomas have the highest survival rate, with statistically significant difference from other tumours $(p=0.015)$. We estimated a mean of 12.25 treated cases per year by each paediatric neurosurgeon at our institution.

Discussion: Our results are globally consistent with those published all over the world, but we reported the highest survival rates. The number of cases treated per year by each neurosurgeon is accordant to the recommended.

Conclusion: We showed an improvement when comparing to data previous to 2008 and better results than those from previous studies, namely higher survival at 1-, 3- and 5-years from the diagnosis, with low complication and relapsing rates. Therefore, the referral of primary central nervous system tumours cases to centres with larger experience can be invaluable for the achievement of the best outcomes.

Keywords: Central Nervous System Neoplasms/epidemiology; Central Nervous System Neoplasms/surgery; Child; Neurosurgery; Portugal; Referral and Consultation.

\section{RESUMO}

Introdução: Os tumores primários do sistema nervoso central representam o segundo grupo de neoplasias mais frequente e são a principal causa de morte devido a tumores sólidos em crianças. O nosso estudo teve como objetivos realizar a mais atualizada análise epidemiológica desta doença no norte de Portugal e avaliar o possível benefício da centralização de cuidados.

Material e Métodos: Este estudo de base populacional incluiu todos os tumores primários do sistema nervoso central diagnosticados e histologicamente confirmados em indivíduos menores de 18 anos de idade, que residem no norte do país, desde Janeiro 2008 até Dezembro 2013. Os dados foram obtidos por meio da avaliação dos processos clínicos dos doentes. Nós descrevemos as características das crianças e dos seus tumores e analisámos os quocientes doente: neurocirurgião pediátrico e tipo histológico de tumor: neurocirurgião pediátrico e as taxas de sobrevivência, mortalidade, complicações e recidiva.

Resultados: Foram registados 147 casos. A média de idade ao diagnóstico foi de 8,0 $\pm 5,2$ anos. Os astrocitomas foram o tipo histológico mais frequentemente encontrado (34\%). O tipo histológico foi a única variável com influência estatisticamente significativa na mortalidade $(p=0,001)$. As sobrevivências a um, três e cinco anos relativas ao período entre 2008 - 2013 foram estatisticamente superiores às do intervalo entre 2005 - 2007. Os astrocitomas apresentam a mais alta taxa de sobrevivência, sendo estatisticamente diferente dos outros tipos de tumor $(p=0,015)$. Estimámos uma média de 12,25 casos tratados anualmente por neurocirurgião pediátrico no nosso hospital.

Discussão: Os nossos resultados são, globalmente, consistentes com os encontrados na literatura mundial, mas registrámos taxas de sobrevivência mais altas. O número de casos tratados por neurocirurgião pediátrico está de acordo com o recomendado.

Conclusão: Demonstrámos que houve melhoria dos outcomes em estudo em relação aos obtidos previamente a 2008 e aos reportados por outros estudos, nomeadamente taxas de sobrevivência a um, três e cinco anos após o diagnóstico mais elevadas, com índices de complicações e recidiva baixos. Neste sentido, a referenciação destes casos para centros de vasta experiência pode ser de valor inestimável para se obter os melhores resultados.

Palavras-chave: Criança; Neoplasias do Sistema Nervoso Central/cirurgia; Neoplasias do Sistema Nervoso Central/epidemiologia; Neurocirurgia; Portugal; Referência e Consulta.

\footnotetext{
1. Faculty of Medicine. University of Porto. Porto. Portugal.

2. Department of Internal Medicine. Centro Hospitalar São João. Porto. Portugal.

3. CINTESIS - Center for Health Technology and Services Research. Porto. Portugal.

4. Department of Neurosurgery. Centro Hospitalar São João. Porto. Portugal.

5. Department of Clinical Neurosciences and Mental Health. Faculty of Medicine. University of Porto. Portugal.

$\triangle$ Autor correspondente: Ana Batista. anabatista90@hotmail.com

Recebido: 23 de março de 2015 - Aceite: 10 de agosto de 2015 | Copyright @ Ordem dos Médicos 2016
} 


\section{INTRODUCTION}

Primary central nervous system tumours (PCNST) represent the second most frequent neoplasm (15-20\% of all paediatric malignancies), following haematological cancers, and are the most common group of solid tumours in children. ${ }^{1-4}$ Moreover, they are the leading cause of death from solid tumours in this age range..$^{1,2,4}$

Studies based on PCNST epidemiology report that the incidence is increasing probably because of the improved diagnostic accuracy, better reporting and improved health care accessibility ${ }^{1,2}$ and it varies between countries, child age, type and location of the mass. ${ }^{1}$

This group of heterogeneous neoplasia has a large prognosis variation, concerning the different histology subtypes. Thus, it is of great importance improving diagnosis strategies and driving treatments. Supporting this idea, an European population-based survival analysis showed that there has been a significant improvement of this outcome over the last 30 years. $^{3}$

In Portugal, on January $10^{\text {th }} 2008$, the Prevention and Control of Oncologic Diseases National Programme established that an Integrated Referral Network in Oncology (IRNO) should be built as a system that includes different types of institutions, which articulate mutually, in order to provide oncology specialised care, in a global and integrated perspective. The necessary capacity, resources and facilities to ensure that quality of care in the north are shared by Hospital São João (HSJ) and Portuguese Oncology Institute Francisco Gentil in Porto (IPOPFG). The aim of Decree-Law $n^{\circ} 6 / 2008$ was to build a paediatric oncology specialised care network that articulates, in a complementary and cooperative basis, healthcare provider institutions in order to facilitate the creation of conditions of prosecution of the following goals: a) improving of quality of care given to children suffering from oncologic pathology; b) creation of conditions that ease the best performance of all integrated institutions in their mission; c) development of scientific research in paediatric oncology; d) promotion of continuing education of the healthcare staff. It was determined that paediatric oncology referral of newly diagnosed patients in the north region should obey to the following criteria: a) children suffering from haematological cancers are addressed to IPOPFG; b) children suffering from neurological cancers are addressed to HSJ; c) children suffering from other solid tumours can be orientated to either centre. ${ }^{5}$ Our hospital is staffed by 2 paediatric neurosurgeons, of which one is in senior-level and the other has less experience.

The elaboration of this population-based study aimed to provide the most up-to-date epidemiological analysis of PCNST in children living in the north of the country and to explore a possible effect of the centralisation of care on outcomes, comparing the data before and after the law had been proclaimed.

\section{MATERIAL AND METHODS}

We conducted an observational study to assess the main characteristics of paediatric population with a primary central nervous system tumour (PCNST). We also included patients with skull tumours, because these are treated by paediatric neurosurgeons as well. Exclusion criteria were based on inexistent classification for a tumour in the ICD-O 3 classification, ${ }^{6}$ histological result not revealing a neoplasm and inexistent histological or surgical report.

Gathered data included age, sex, year of intervention, histological diagnosis according to ICD-O 3 classification, ${ }^{6}$ site of the tumour (supratentorial, infratentorial, spinal cord or cauda equina and skull), surgery (biopsy/resection) and the number of paediatric neurosurgeons at the Neurosurgery Department of our hospital. To facilitate the comparison with previous studies, sometimes, the sample was stratified by age groups $(0-4 ; 5-9 ; 10-14 ; 15-18)$. We clustered the histological types of tumour in 8 groups: 1) Astrocytomas, which include fibrillary, pilomyxoid, pilocytic and subependymal giant cells astrocytoma and pleomorphic xanthoastrocytoma; 2) Other gliomas (low grade glioma, glioblastoma, oligodendroglioma, anaplastic oligodendroglioma, ependymoma, angiocentric glioma and oligoastrocytoma); 3) Choroid plexus tumours (papilloma and carcinoma); 4) Embryonal tumours (medulloblastoma, supratentorial PNET, neuroblastoma and atypical teratoid/ rhabdoid tumour); 5) Other neuroepithelial tumours (ganglioglioma, central neurocytomaand pineal parenchymal tumour); 6) Craniopharyngioma; 7) Skull tumours (dermoid cyst, fibrous bone tumour, neuroectodermal tumour and aneurysmatic bone cyst); 8) Other tumours (neurofibroma, meningioma, hemangioblastoma, germinoma, mature teratoma, cavernous angioma, gliomatosis cerebri and histiocytosis).

Relapse was defined as a growth of tumour after treatment ${ }^{7}$ and complication as any adverse event (fluid leakage, hydrocephalus, infection) after the primary surgery, both associated with need for reoperation.

We gathered data from January $1^{\text {st }} 2008$ to December $31^{\text {st }}$ 2013. Patients with a PCNST with an age below 18 years old were identified from operating room records. The follow-up period ended by December $31^{\text {st }} 2014$. These data were compared to those existing previously to 2008, obtained by courtesy of RORENO (Regional Oncology Reports of North).

We describe patient: paediatric neurosurgeon (surgeon volume) and histological type of tumour: paediatric neurosurgeon ratio and the 1-, 3- and 5-year survivals for the two different periods of time (before and after 2008). Other outcomes achieved were frequencies of each histological type (distribution by sex and age groups), of each WHO grade and of the location of tumour, of modality of surgery (biopsy versus resection) and geographical distribution of cases; relapsing, complication and mortality rates.

Data were analysed using SPSS software, version 22.0 (IBM Corporation, New York, USA). Numeric variables are summarised through mean \pm standard deviation (SD), minimum and maximum; qualitative variables by absolute 
and relative frequencies. We used independent variable Chisquare Test for the qualitative and T-Test for the quantitative variables, regarding univariate analysis. In multivariate analysis, we used Logistic and Cox Regressions. KaplanMeyer methodology was applied to assess survival over time and Log-Rank Test to compare survivals. All calculated $p$ values refer to two-tailed probabilities and are considered of statistically significance for $<0.05$.

The study was approved by CES (Ethical Committee for Health of Hospital São João).

\section{RESULTS}

A total of 152 patients with PCNST were identified. Five patients were excluded: 1 case without histological confirmation; 1 case classified as malakoplakia; 1 case classified as a possible rhabdoid tumour, but it could not be proven because the patient died before the histological report elaboration; 1 case misclassified as neoplasm, but instead it was a granulomatous inflammatory process; 1 case of acute myeloid leukemia. Thus, the final sample size is 147 cases, which are characterised in Table 1.

Table 1 - Sample characteristics, n (\%)

\begin{tabular}{|c|c|c|c|c|c|}
\hline & & \multirow{2}{*}{ Total } & \multicolumn{3}{|c|}{ Mortality } \\
\hline & & & No & Yes & $P$ \\
\hline \multirow{2}{*}{ Sex } & $\mathrm{F}$ & $60(40.8)$ & $56(41.8)$ & $4(30.8)$ & 0.440 \\
\hline & $M$ & $87(59.2)$ & $78(58.2)$ & $9(69.2)$ & \\
\hline $\begin{array}{l}\text { Mean } \pm \text { SD } \\
(\min -\max )\end{array}$ & & $\begin{array}{c}8.0 \pm 5.2 \\
(0-17)\end{array}$ & $\begin{array}{c}8.2 \pm 5.3 \\
(0-17)\end{array}$ & $\begin{array}{c}5.5 \pm 4.0 \\
(1-13)\end{array}$ & 0.076 \\
\hline \multirow{4}{*}{ Age (years) } & $0-4$ & $48(32.7)$ & $41(30.6)$ & $7(53.8)$ & 0.177 \\
\hline & $5-9$ & $38(25.9)$ & $34(25.4)$ & $4(30.8)$ & \\
\hline & $10-14$ & $38(25.9)$ & $36(26.9)$ & $2(15.4)$ & \\
\hline & $15-18$ & $23(15.5)$ & $23(17.2)$ & $0(0)$ & \\
\hline \multirow{6}{*}{ District } & Porto & $78(53.4)$ & $72(54.1)$ & $6(46.2)$ & 0.715 \\
\hline & Braga & $32(21.9)$ & $30(22.6)$ & $2(15.4)$ & \\
\hline & Viana do Castelo & $6(4.1)$ & $5(3.8)$ & $1(7.7)$ & \\
\hline & Vila Real & $4(2.7)$ & $4(3)$ & $0(0)$ & \\
\hline & Bragança & $1(0.7)$ & $1(0.8)$ & $0(0)$ & \\
\hline & Other regions & $25(17.2)$ & $21(15.8)$ & $4(30.8)$ & \\
\hline \multirow{4}{*}{ Site of tumour } & Supratentorial & $73(50.0)$ & $67(50.4)$ & $6(46.2)$ & 0.638 \\
\hline & Infratentorial & $53(36.4)$ & $49(36.8)$ & $4(30.8)$ & \\
\hline & Spinal Cord & $10(6.8)$ & $8(6)$ & $2(15.4)$ & \\
\hline & Skull & $10(6.8)$ & $9(6.8)$ & $1(7.7)$ & \\
\hline \multirow{2}{*}{ Surgery } & Biopsy & $13(9.0)$ & $11(8.3)$ & $2(16.7)$ & 0.330 \\
\hline & Resection & $132(91.0)$ & $122(91.7)$ & $10(83.3)$ & \\
\hline \multirow{2}{*}{ Complications } & No & $136(92.5)$ & $123(91.8)$ & $13(100)$ & 0.283 \\
\hline & Yes & $11(7.5)$ & $11(8.2)$ & $0(0)$ & \\
\hline \multirow{2}{*}{ Relapse } & No & $131(89.1)$ & $119(88.8)$ & $12(92.3)$ & 0.699 \\
\hline & Yes & $16(10.9)$ & $15(11.2)$ & $1(7.7)$ & \\
\hline \multirow{5}{*}{ WHO Grade } & Not applicable & $16(10.9)$ & $14(10.4)$ & $2(15.4)$ & 0.001 \\
\hline & I & $62(42.2)$ & $61(45.5)$ & $1(7.7)$ & \\
\hline & II & $28(19.0)$ & $27(20.1)$ & $1(7.7)$ & \\
\hline & III & $6(4.1)$ & $4(3)$ & $2(15.4)$ & \\
\hline & IV & $35(23.8)$ & $28(20.9)$ & 7 (53.8) & \\
\hline Mortality & & & $134(91.2)$ & $13(8.8)$ & \\
\hline
\end{tabular}

$p<0.05$; SD: standard deviation; Min: minimum; Max: maximum; F: female; M: male. Chi-square test was used for qualitative variables and T-test for quantitative variables. 
This sample includes mostly boys (59.2\%), with a mean (SD) age of children of 8 (5.2) years old at the moment of diagnosis. The mean (SD) time of follow-up was 3.6 (1.9) years. The districts mostly represented were Porto and Braga. Most tumours were supratentorial (50.0\%); resection (versus biopsy) was the surgery modality chosen in $91.0 \%$ of cases; $92.5 \%$ did not suffer any complication, $10.9 \%$ relapsed; and grades I (42.2\%) and II (19.0\%) were the most prevalent. With respect to mortality, at the moment of study, was $8.8 \%$. The mean survival time was 6.4 years (95\% Cl: $6.1-6.7)$.

The only characteristic that was related to increased mortality in univariate analysis was a high WHO grade. A nearly significant trend was observed for age at diagnosis $(p=0.076)$.

Table 2 shows survival at 1-, 3- and 5-years comparing the 2005-2007 and 2008 - 2013 periods. Survival rates were significantly higher at the 2008-2013 period.

We performed two multivariate analyses (Table 3) - Logistic and Cox regressions - age, sex, WHO grade, surgery modality and relapse occurrence as independent variables and mortality as dependent variable. The location and complication occurrence variables were not included in this analysis because of estimation problems (non-convergent results). They showed that WHO tumour graduation was the only variable of statistically significant influence in mortality.

Log-Rank test identified statistically significant difference $\left(\chi^{2}=16.30 ; p<0.001\right)$ in survival between various tumour grades. Comparing different WHO tumour grades, we found statistically significant differences in survival between grade I (mean survival: 6.6 years, 95\% Cl: $6.4-6.8$ ) and grades
III (mean survival: 4.5 years, $95 \% \mathrm{Cl}: 2.6-6.5 ; \chi^{2}=136.62$; $p<0.001)$ and IV (mean survival: 5.4 years, $95 \% \mathrm{Cl}: 4.6$ - 6.2; $\chi^{2}=10.10 ; p=0.001$ ) and between grade II (mean survival: 6.7 years; $95 \% \mathrm{Cl}: 6.3-7.1)$ and grade III $\left(\chi^{2}=\right.$ $6.02 ; p=0.014)$. Mean time survival per WHO grade are shown in Table 4.

Table 5 presents the distribution of tumours by histological diagnosis according to age group and sex. We observed statistically significant differences between age groups in relation to histology. Astrocytomas are the most frequent type of tumour in all age groups. Other gliomas and craniopharyngioma were more common in children between 5 and 9 years old ( $21.1 \%$ and $15.8 \%$, respectively). Choroid plexus and embryonal tumours are more seen in children between 0 - 4 years old (10.4\% and $29.2 \%$, respectively) and other neuroepithelial and skull tumours are more frequent in age group of 15 - 18 years old (13.0\%).

We analysed the distribution of site of tumour according to age groups and sex. There is a statistically significant difference among age group and sex related to the site. Supratentorial is the most frequent location of tumours in the ages between 5 and 18 years old and in girls (61.7\%). Infratentorial is more common between 0 - 4 years old $(51.1 \%)$ and in boys $(45.3 \%)$.

Table 6 shows the patient:paediatric neurosurgeon and histological type of tumour paediatric neurosurgeon ratios per year.

Finally, we compared the survival time for the 3 most common types of tumour (astrocytoma, other gliomas and embryonal tumours) and observed statistically significant differences $\left(\chi^{2}=8.42 ; p=0.015\right)$ using Log-Rank test. Astrocytomas (mean survival: $6.8,95 \% \mathrm{Cl}: 6.6-7.1$ ) have

Table 2 - Observed survival

\begin{tabular}{|c|c|c|c|c|c|}
\hline \multicolumn{3}{|c|}{$2005-2007(n=69)$} & \multicolumn{3}{|c|}{$2008-2013(n=147)$} \\
\hline Years from diagnosis & Survival (\%) & $95 \% \mathrm{Cl}$ & Years from diagnosis & Survival (\%) & $95 \% \mathrm{Cl}$ \\
\hline 1 & 78.3 & $66.6-86.3$ & 1 & 94.6 & $90.9-98.2$ \\
\hline 3 & 69.6 & $57.2-79.0$ & 3 & 92.1 & $87.5-96.6$ \\
\hline 5 & 65.2 & $52.8-75.2$ & 5 & 89.7 & $84.2-95.2$ \\
\hline
\end{tabular}

Cl: confidence interval

Table 3 - Multivariate analysis

\begin{tabular}{|c|c|c|c|c|c|c|}
\hline & \multicolumn{3}{|c|}{ Logistic Regression } & \multicolumn{3}{|c|}{ Cox Regression } \\
\hline & OR & $95 \% \mathrm{Cl}$ & $p$ & HR & $95 \% \mathrm{Cl}$ & $p$ \\
\hline Age & 0.84 & $0.7-1.01$ & 0.061 & 0.89 & $0.77-1.03$ & 0.091 \\
\hline Male sex & 1.08 & $0.22-5.28$ & 0.922 & 1.26 & $0.30-5.35$ & 0.757 \\
\hline WHO Grade I & 0.09 & $0.01-0.80$ & $0.031^{*}$ & 0.10 & $0.01-0.84$ & $0.033^{*}$ \\
\hline WHO Grade II & 0.20 & $0.02-1.89$ & 0.160 & 0.24 & $0.03-2.02$ & 0.187 \\
\hline WHO Grade III & 5.85 & $0.51-67.03$ & 0.155 & 2.73 & $0.52-14.4$ & 0.234 \\
\hline Surgery - resection & 0.56 & $0.07-4.21$ & 0.573 & 0.46 & $0.08-2.66$ & 0.387 \\
\hline Relapse occurrence & 0.38 & $0.03-4.71$ & 0.454 & 0.60 & $0.07-5.2$ & 0.640 \\
\hline
\end{tabular}

${ }^{*} p<0.05$; OR: odds ratio; HR: hazard ratio; Cl: confidence interval. 
Table 4 - Mean time survival according to WHO tumour graduation

\begin{tabular}{lcc}
\hline & Mean (years) & $95 \% \mathrm{Cl}$ \\
\hline Grade I & 6.6 & $6.4-6.8$ \\
Grade II & 6.7 & $6.3-7.1$ \\
Grade III & 4.5 & $2.6-6.5$ \\
Grade IV & 5.4 & $4.6-6.2$ \\
\hline
\end{tabular}

Cl: confidence interval

a statistically significant higher survival than other gliomas (mean survival: $5.9,95 \% \mathrm{Cl}: 5.0-6.9 ; \chi^{2}=4.19 ; p=0.041$ ) and than embryonal tumours (mean survival: $5.3 ; 95 \% \mathrm{Cl}$ : $\left.4.4-6.1 ; \chi^{2}=8.99 ; p=0.003\right)$. We did not find statistically significant difference in survival between other gliomas and embryonal tumours $\left(\chi^{2}=0.40 ; p=0.527\right)$.

\section{DISCUSSION}

This work included all newly diagnosed and histologically confirmed primary central nervous system tumours (PCNST) in children below the age of 18, living in the north of Portugal, from 2008 to 2013. PCNST include all benign and malignant forms of tumours located on central nervous system (CNS), including its envelopes (meninges and bone) and nerves inside the skull and vertebrae, in other words, tumours that are always managed by neurosurgery. ${ }^{1}$ The ascertainment of the different histology of tumours was based on ICD-O 3 classification ${ }^{6}$ to facilitate comparisons between series from the literature. The main goals of our research were to provide the most updated epidemiological analysis of PCNST in children living in the north of the country and to explore a possible effect of the centralisation of care on outcomes, comparing data before and after a law had been promulgated, in 2008. That law established that children and teens suffering from neurological cancers must be addressed to Hospital São João. ${ }^{5}$

\section{Strengths and limitations}

There is no other research similar to this in our country, so the importance of our study lays on this point, because we performed an epidemiological update, and simultaneously, we assessed the quality of care given at our hospital (measured by observed survival, mortality, complication and relapsing rates and patient: neurosurgeon ratio) after the decision of centralisation of treatment of PCNST by comparing it with the situation in other countries (France, ${ }^{1}$ Canada, ${ }^{2}$ Australia, ${ }^{4}$ United States of America, ${ }^{8}$ United Kingdom ${ }^{9,10}$ and Norway ${ }^{11,12}$ ). Our analysis is a population-based one, which means that we report results from all cases of PCNST that were diagnosed in the north of Portugal, including older children (above 15 years old) in contrast to other studies. ${ }^{2,9,13}$ For the first time, we describe the association between mortality, age and WHO grade of tumour.

Our study can be limited by the restricted covered area, because we collected data only related to the north and it may not be representative of the whole country, since the incidence rate of the different tumours as well as the quality of care and material and personnel resources can vary from a hospital to another. Another limitation is the narrow sample size, which is a consequence of small number of inhabitants and of short period of data collecting. The follow-up period varied from 1 to 7 years, concerning children for whom diagnosis was established in December 2013 or January 2008, respectively, which can influence the interpretation of mortality and survival rates. There may be potential confounders, such as tumour size and actual resection grade, precluding a reliable definition of the site of tumour. Presence of comorbidities or other factors related to survival may bias our results. There could be inter-observer variability, because there are different physicians handling children tumours and different pathologists encoding the histological diagnosis and this can jeopardise the accuracy of our findings. We do not aim to argue about the validity of the diagnosis established by both professionals, but only to report the epidemiology of this kind of tumours, and this can reflect the difficulty in homogenizing the histological diagnosis all over the world. ${ }^{1,2,4,11}$

\section{Main results and comparison with previous studies}

The incidence rate of infantile PCNST remains

Table 5 - Distribution of tumours by histological diagnosis according to age and sex

\begin{tabular}{|c|c|c|c|c|c|c|c|c|c|}
\hline & \multicolumn{4}{|c|}{ Age (\%) } & \multicolumn{4}{|c|}{$\operatorname{Sex}(\%)$} & \multirow{2}{*}{$\begin{array}{c}\text { Total } \\
(\%)\end{array}$} \\
\hline & $0-4$ & $5-9$ & $10-14$ & $15-18$ & م & $\mathbf{F}$ & M & 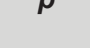 & \\
\hline Astrocytomas & $15(31.3)$ & $9(23.7)$ & $15(39.5)$ & $11(47.8)$ & $0.024^{*}$ & $24(40.0)$ & $26(29.9)$ & 0.339 & $50(34)$ \\
\hline Other gliomas & $6(12.5)$ & $8(21.1)$ & $5(13.2)$ & $2(8.7)$ & & $7(11.7)$ & $14(16.1)$ & & $21(14.3)$ \\
\hline Choroid plexus tumours & $5(10.4)$ & $0(0)$ & $1(2.6)$ & $1(4.3)$ & & $1(1.7)$ & $6(6.9)$ & & $7(4.8)$ \\
\hline Embryonal tumours & $14(29.2)$ & $8(21.1)$ & $7(18.4)$ & $2(8.7)$ & & $10(16.7)$ & $21(24.1)$ & & $31(21.1)$ \\
\hline Other neuroepithelial tumours & $1(2.1)$ & $2(5.3)$ & $4(10.5)$ & $3(13)$ & & $6(10)$ & $4(4.6)$ & & $10(6.8)$ \\
\hline Craniopharyngioma & $0(0)$ & $6(15.8)$ & $2(5.3)$ & $0(0)$ & & $3(5)$ & $5(5.7)$ & & $8(5.4)$ \\
\hline Skull tumours & $4(8.3)$ & $1(2.6)$ & $0(0)$ & $3(13)$ & & $5(8.3)$ & $3(3.4)$ & & $8(5.4)$ \\
\hline Other tumours & $3(6.3)$ & $4(10.5)$ & $4(10.5)$ & $1(4.3)$ & & $4(6.7)$ & $8(9.2)$ & & $12(8.2)$ \\
\hline
\end{tabular}


Table 6 - Patient: paediatric neurosurgeon and histological type of tumor: paediatric neurosurgeon ratios per year

\begin{tabular}{|c|c|c|c|c|c|c|}
\hline Year & $\mathbf{N}$ & & $\begin{array}{l}\text { Patient: paediatric } \\
\text { neurosurgeon ratio }\end{array}$ & Histological type of tumour & $\mathbf{N}$ & $\begin{array}{l}\text { Histological type of tumour: } \\
\text { paediatric neurosurgeon ratio }\end{array}$ \\
\hline \multirow{8}{*}{2008} & \multirow{8}{*}{29} & \multirow{8}{*}{14.5} & & Astrocytoma & 5 & 2.5 \\
\hline & & & & Other gliomas & 7 & 3.5 \\
\hline & & & & Choroid plexus tumours & 1 & 0.5 \\
\hline & & & & Embryonal tumours & 5 & 2.5 \\
\hline & & & & Other neuroepithelial tumours & 2 & 1.0 \\
\hline & & & & Craniopharyngioma & 2 & 1.0 \\
\hline & & & & Skull tumours & 3 & 1.5 \\
\hline & & & & Other tumours & 4 & 2.0 \\
\hline \multirow{8}{*}{2009} & \multirow{8}{*}{19} & \multirow{8}{*}{\multicolumn{2}{|c|}{9.5}} & Astrocytoma & 5 & 2.5 \\
\hline & & & & Other gliomas & 3 & 1.5 \\
\hline & & & & Choroid plexus tumours & 1 & 0.5 \\
\hline & & & & Embryonal tumours & 4 & 2.0 \\
\hline & & & & Other neuroepithelial tumours & 2 & 1.0 \\
\hline & & & & Craniopharyngioma & 1 & 0.5 \\
\hline & & & & Skull tumours & 1 & 0.5 \\
\hline & & & & Other tumours & 2 & 1.0 \\
\hline \multirow{8}{*}{2010} & \multirow{8}{*}{29} & \multirow{8}{*}{\multicolumn{2}{|c|}{14.5}} & Astrocytoma & 11 & 5.5 \\
\hline & & & & Other gliomas & 3 & 1.5 \\
\hline & & & & Choroid plexus tumours & 2 & 1.0 \\
\hline & & & & Embryonal tumours & 8 & 4.0 \\
\hline & & & & Other neuroepithelial tumours & 0 & 0.0 \\
\hline & & & & Craniopharyngioma & 2 & 1.0 \\
\hline & & & & Skull tumours & 2 & 1.0 \\
\hline & & & & Other tumours & 1 & 0.5 \\
\hline \multirow{8}{*}{2011} & \multirow{8}{*}{23} & \multirow{8}{*}{\multicolumn{2}{|c|}{11.5}} & Astrocytoma & 11 & 5.5 \\
\hline & & & & Other gliomas & 2 & 1.0 \\
\hline & & & & Choroid plexus tumours & 0 & 0.0 \\
\hline & & & & Embryonal tumours & 6 & 3.0 \\
\hline & & & & Other neuroepithelial tumours & 0 & 0.0 \\
\hline & & & & Craniopharyngioma & 1 & 0.5 \\
\hline & & & & Skull tumours & 0 & 0.0 \\
\hline & & & & Other tumours & 3 & 1.5 \\
\hline \multirow{8}{*}{2012} & \multirow{8}{*}{19} & \multirow{8}{*}{\multicolumn{2}{|c|}{9.5}} & Astrocytoma & 6 & 3.0 \\
\hline & & & & Other gliomas & 4 & 2.0 \\
\hline & & & & Choroid plexus tumours & 1 & 0.5 \\
\hline & & & & Embryonal tumours & 3 & 1.5 \\
\hline & & & & Other neuroepithelial tumours & 2 & 1.0 \\
\hline & & & & Craniopharyngioma & 1 & 0.5 \\
\hline & & & & Skull tumours & 2 & 1.0 \\
\hline & & & & Other tumours & 0 & 0.0 \\
\hline \multirow{8}{*}{2013} & \multirow{8}{*}{28} & \multirow{8}{*}{\multicolumn{2}{|c|}{14.0}} & Astrocytoma & 12 & 6.0 \\
\hline & & & & Other gliomas & 2 & 1.0 \\
\hline & & & & Choroid plexus tumours & 2 & 1.0 \\
\hline & & & & Embryonal tumours & 5 & 2.5 \\
\hline & & & & Other neuroepithelial tumours & 4 & 2.0 \\
\hline & & & & Craniopharyngioma & 1 & 0.5 \\
\hline & & & & Skull tumours & 0 & 0.0 \\
\hline & & & & Other tumours & 2 & 1.0 \\
\hline
\end{tabular}


controversial. ${ }^{1}$ In north of our country, the incidence rate ranged from 3.33 (between 2005-2007) to 3.31 per 100000 children (between 2008-2009). This data was kindly provided by RORENO (Regional Oncology Reports of North) and is in agreement with that observed in all Europe (2.99 per 100000 children under 15 years old), and slightly lower than that reported in United States of America (4.61 per 100000 children under 15 years old, and 4.53 for children under 20 years old). ${ }^{1}$

As shown in previous works, there is a clear predominance of boys suffering from this disease $(59.2 \%$ of our sample size) with gender ratio of $1.45: 1$, which is accordant to those found all over the world ranging from 1.2 to $2.1 .{ }^{1}$ A study from Canada showed an incidence of $56.8 \%$ in boys, reporting that medulloblastoma (that belongs to the embryonal type of tumours) has the highest male predominance. ${ }^{2}$ However, there are some histological subtypes which are more frequent in boys (embryonal tumours and germ cell tumours), while others are more identified in girls (meningioma and ependymoma)., ${ }^{1,2}$ Our study reveals an obvious predominance of other gliomas (gliomas excluding astrocytomas), embryonal and choroid plexus tumours in boys, while other neuroepithelial and skull tumours are more common in girls.

To facilitate comparison with other studies, we divided the sample into age and histological diagnosis groups. Like previous studies, ${ }^{1,2,4,11}$ we have demonstrated that astrocytomas are the most frequent kind of PCNST seen in clinical practice (34.0\%). Embryonal tumours are the second most common (21.1\% versus 15.3 - $19.1 \%$ reported abroad $)^{1,2,4,11}$ and affect frequently the youngest children (0 4 years old), as it happens to with choroid plexus tumours. ${ }^{1,2}$ Craniopharyngioma is more frequent in the 5 - 9 and other neuroepithelia tumours in the $15-18$ age groups, ${ }^{1}$ in concordance to our results.

According to the location, the supratentorial is the most frequent site $(50 \%)$, followed by infratentorial $(36.3 \%)$, and then spinal cord and skull $(10 \%)$, which is in agreement with the literature. ${ }^{1,4}$ The supratentorial tumours are more common in older children and in girls; the infratentorial in the youngest and in boys, with statistically significant difference, as we reported.

The survival assessed in our study at 1-, 3- and 5years, concerning data collected from 2008 to 2013, was statistically higher than that found in 2005 - 2007 period and slightly higher than that reported in a Norwegian paper (91\% (95\% Cl: 86 - 93), 82\% (95\% Cl: 79 - 85) and $79 \%(95 \% \mathrm{Cl}: 75-82)$, respectively). ${ }^{11}$ A work taken in Australia showed 1- and 5-year survivals of $89 \%$ and $80 \%$, respectively. ${ }^{4}$ Canadian and United States of America studies reported much lower 5 -year survival than us $(30 \%$ and $66 \%$, respectively). ${ }^{2}$ We found the highest survival rate for astrocytomas with statistically significant difference from other gliomas and embryonal tumours, supporting what they reported in Canada. ${ }^{2}$ Multivariate analysis revealed that WHO tumour grade was the only variable of statistically significant influence in mortality. On contrary, a review article from Canada and United States of America stated that young age was the unique factor strongly associated with adverse outcome. ${ }^{2}$

Albeit some can report that PCNST in children are very refractory to treatments and treatments themselves bear risks and potential morbidity, ${ }^{2}$ our results show an improvement of survival over time, as it does an European overall survival analysis ${ }^{3}$ and an Australian work. ${ }^{4}$ Moreover, we found low complication $(7.5 \%)$ and relapsing $(10.9 \%)$ rates, with need for reoperation. This could be attributable to many factors, but we believe it is a consequence of better reporting, improved accessibility to healthcare services, ${ }^{2,3}$ improved socio-economic conditions, more effective drugs, greater intensity and precocity of treatment, better accomplishment to standardised protocols, more effective supportive therapy ${ }^{3,13}$ and modern imaging procedures that enable an accurate and anticipated diagnosis.

\section{Health care models and outcomes}

For many surgical procedures, hospitals where a large number of patients are treated (high-volume hospitals) reveal lower mortality and improved survival rates, ${ }^{8,14}$ because they tend to have much larger facilities, such as a range of specialist and technology-based services, better-equipped intensive care units and more experienced surgeons..$^{8,12}$ Studies from United States of America and Canada have reported lower mortality and morbidity rates and better surgical resection rates when tumours are handled by 'highvolume neurosurgeons' at 'high-volume centres'. 9-11,13 If so, it would be advisable directing patients to the providers who are likely to achieve the best results..$^{8,9,13}$ However, the necessary degree of centralisation to reach the best or optimal benefit is not known. ${ }^{12}$ Furthermore, a single research reported lower survival at paediatric oncology centres, ${ }^{13}$ possibly because these institutions attend a much larger proportion of cases of advanced disease. ${ }^{12,13}$ Berry et al (2008), found an association between low volume surgeons and lower revision rates of CSF shunting. They gave an explanation to this: more complex revisions could be more often referred to high volume surgeons, and low volume surgeons, more inexperienced, could be assisted by more experienced ones. Regarding craniotomy for brain tumour, our results are similar to the ones from the Royal College of Surgeons of England published in 2007: lower inhospital mortality and higher likelihood of being discharged home for high volume hospitals and surgeons. ${ }^{10}$

A British study states that, whenever possible, paediatric and adult neurosurgery services should work together not only for sharing ideas but for the best use of scarce resources and staff. This benefit is more easily demonstrated by the collaboration of adult neurosurgeons in the treatment of children with conditions that are more frequent in elderly people - e.g. pituitary tumours, acoustic neuromas, cerebral aneurysms - and by the assistance of paediatric neurosurgeons in management of adults with difficult hydrocephalus, spinal dysraphism, etc.. ${ }^{9}$

In 2001, the Society of British Neurological Surgeons 
set out recommendations concerning safety on paediatric neurosurgery: children and their healthcare needs must be given higher priority; their needs are different from those of adults; specialised care must be concentrated in a limited number of centres where the staff can accumulate the appropriate skills and experience; all personnel who treat children must have training in caring for them. ${ }^{10}$ Taking these principles into account, Safe Paediatric Neurosurgery advise that units undertaking paediatric neurosurgery procedures should be staffed by at least 2 neurosurgeons with a special interest in paediatrics; ${ }^{9}$ children with neurosurgical emergencies requiring urgent intervention should have access to appropriate neurosurgical help within 2 hours; specialist paediatric neurosurgical departments should be able to accept admissions within an adequate timeframe and must have appropriate supportive services; neurosurgeons who provide specialist paediatric care should have a regular commitment to paediatric neurosurgery, including designated theatre and outpatient clinical time and appropriate arrangements for Continuing Medical Education, improving and avoiding loss of skills in this area. ${ }^{10}$

In 2007, the British Royal College of Surgeons updated its endorsements: in order to avoid deskilling, paediatric neurosurgery activity in UK should be concentrated in major centres serving a large volume of population (6 - 8 million) and this would enable sufficient workload to provide the pre- and post-training, opportunities for research and sub-specialisation, and should be staffed by 4 or 5 neurosurgeons; the capacity and capability for occasional, life-saving emergency interventions on children presenting to their nearest general neurosurgical unit should be maintained as far as possible in all neurosurgical centres. Therefore, no specific recommendations about caseload/ volume were made. ${ }^{10}$ The system in UK works as 3 main units offering a separate paediatric neurosurgical on-call rota and in the remaining the patients are managed through adult on-call system, being transferred on next working day to the care of a paediatric neurosurgeon. Moreover, they report that each surgeon manages 5-10 paediatric CNS tumour cases per year, although there is no available morbidity or mortality data ${ }^{9}$. These assumptions are supported by an American research about surgeon volume and operative mortality. ${ }^{8}$ Like most studies, we were unable to determine individual surgeon volumes, but, in our research of 6 consecutive years, we report a mean of 12.25 treated cases of PCNST per year by each paediatric neurosurgeon, which is superior to the reported by Royal College of Surgeons. A study from Norway found no survival advantage associated with high surgical volumes. ${ }^{11}$ They affirm that PCNST have very low incidence and are so diverse both in location and histopathology that the chance of acquiring extensive personal surgical experience for most entities can be limited, even in the larger centres..$^{9,11,12}$ So, a neurosurgeon could take long periods of time with no contact to some kind of those types, as we have shown, not managing any
Skull tumours in 2011 and 2013. For the authors, the quality of care systems was more important than volume itself in determining the overall quality of surgical care at a treatment centre. For many procedures, the observed advantage for high-volume hospitals in operative mortality disappears when adjusting for surgeon volume. ${ }^{8,11,12}$ Furthermore, for the Norwegian investigators, centralisation of care would have more costs to the government and families, would increase the social effect of the disease by tearing families apart and hamper the routine check-ups. The occurrence of complications is more common after discharge and these are best managed by the operating surgeon. The distance from the hospital where patient was initially treated can preclude his transfer to there and this can lead to misinterpretation of symptoms by other physicians, longer delays in treatment and more ineffective approaches. ${ }^{12}$ They believed that, for many paediatric neurosurgical procedures, the surgeon often needs to trust in 'transferable skills' based on the experience he takes from operations in the same anatomical locations or from histopathological cases in adult patients, rather than experience from exact analogous cases. ${ }^{11,12}$ Notwithstanding, some nations are currently applying a mandatory revalidation of surgeon skills. In USA, it happens every 10 years and a paediatric neurosurgeon must perform 125 procedures per year or three quarters of his annual workload must be on children treatment $^{9}$

\section{CONCLUSION}

We describe epidemiological, organisational and outcome data from the north of Portugal related to the primary central nervous system tumours in children, as there was no other research similar to this in our country, regarding the period 2008-2013. We show an improvement when comparing to data previous to 2008 and better results than those from previous studies, namely higher survival at 1-, 3- and 5-years from the diagnosis, with low complication and relapsing rates. We found the highest survival rate for astrocytomas with statistically significant difference from other tumours and that WHO tumour grade was the only variable with influence in mortality. Therefore, the referral of PCNST cases to centres with larger experience can be invaluable for the achievement of the best outcomes. In a future perspective, knowledge in this area can direct further initiatives in research, surveillance, prevention, possible screening, diagnosis, treatment and follow-up.

\section{PROTECTION OF HUMANS AND ANIMALS}

The authors declare that the study was approved by CES (Ethical Committee for Health of Hospital São João) and the procedures were followed according to the Helsinki Declaration of the World Medical Association.

\section{DATA CONFIDENTIALITY}

The authors declare having followed the protocols in use at their working center regarding patients' data publication. 


\section{CONFLICTS OF INTEREST}

The authors declare that there are no conflicts of interest.

\section{REFERENCES}

1. Bauchet L, Rigau V, Mathieu-Daudé H, Fabbro-Peray P, Palenzuela G, Figarella-Branger $\mathrm{D}$, et al. Clinical epidemiology for childhood primary central neurvous system tumors. J Neurooncol. 2009;92:87-98.

2. Kaderali Z, Lamberti-Pasculli M, Rutka J. The changing epidemiology of paediatric brain tumours: a review from the Hospital for Sick Children. Childs Nerv Syst. 2009;25:787-93.

3. Arndt V, Kaatsch P, Steliarova-Foucher E, Peris-Bonet R, Brenner H. Up-to-date monitoring of childhood cancer long-term survival in Europe: central neurvous system tumours. Ann Oncol. 2007;18:1734-42.

4. Ramanan $M$, Chaseling $R$. Paediatric brain tumours treated at a single, tertiary paediatric neurosurgical referral centre from 1999 to 2010 in Australia. J Clin Neurosci. 2012;19:1387-91.

5. Portugal. Ministério da Saúde. Despacho Normativo 6/2008 de 10 de Janeiro. Diário da República. 2008; $2^{\text {nd }}$ series, number 30:5444.

6. Louis D, Ohgaki H, Wiestler O, Cavenee W, Burger P, Jouvet A et al. The 2007 WHO Classification of Tumours of the Central Nervous System. Acta Neuropathol. 2007;114:97-109.

7. Tse V, Babu H. Recurrent malignant primary brain tumor: the pathophysiology and management, molecular targets of CNS tumor. In: InTech. Dr. Miklos Garami editor. [consulted 2014 Sep 2]; Available from: http://www.intechopen.com/books/molecular-targets-of-cns-tumors/

\section{FUNDING SOURCES}

No subsidies or grants contributed to this work.

recurrent-malignant-primary-brain-tumor-the-pathophysiology-andmanagement.

8. Birkmeyer J, Stukel T, Siewers A, Goodney P, Wennberg D, Lucas F. Surgeon volume and operative mortality in the United States. N Engl J Med. 2003;349:2117-27.

9. Chumas P, Pople I, Mallucci C, Steers J, Crimmins D. British paediatric neurosurgery - a time for change?. Br J Neurosurg. 2008;22:719-28.

10. The Royal College of Surgeons of England. Children's surgery - a first class service. London: RCSE; July 2007. [consulted 2013 Dec 10]; Available from: https://www.rcseng.ac.uk/publications/docs/CSF.html.

11. Solheim O, Salvesen O, Cappelen J, Johannesen T. The impact of provider surgical volumes on survival in children with primary tumors of the central nervous system - a population-based study. Acta Neurochir. 2011;153:1219-29.

12. Solheim O, Cappelen J. Bigger is bigger. Better is better. Acta Neurochir. 2011;153:1237-43.

13. Stiller C. Centralisation of treatment and survival rates for cancer. Archives of Disease in Childhood. 1988;63:23-30.

14. Selby P, Gillis C, Haward R. Benefits from specialised cancer care. Lancet. 1996;348:313-8. 